\title{
Spatial Analysis and Evaluation of Consolidation Potential of Rural Residential Area based on GIS in Jv County
}

\author{
Mingli Chen ${ }^{1}$,Peiru Liu ${ }^{1, a *}$,Xiaoguang Zhang ${ }^{1, b *}$, Jifang Cui ${ }^{2}$, Shujian HE ${ }^{2}$ and \\ Xiaojie $\mathrm{Yu}^{1}$
}

${ }^{1}$ College of Resource and Environment, Qingdao Agricultural University, 700 Changcheng Road, Qingdao, 266109, China

${ }^{2}$ Hailixin Land and Real Estate Appraisal Limited Company, 780-6 Lan-ao Road,

Qingdao, 266200, China

a Corresponding author1 email:cml0451@126.com

b Corresponding author2 email:zhangxg_66@sina.com

\begin{abstract}
Key words: Consolidation potential of rural residential area, GIS, spatial analysis, the method of per capita construction land, potential coefficient

Abstract: The potential evaluation of rural residential area can assist the choosing of urban construction land, the plan of land renovation, and the construction of rural-urban integration. The current number of village is very large in southern part of Shandong, and distribution character of the villages is not unified. The serious abuse of rural construction land causes obvious regional differences. In this paper, Jv County is selected to carry out our analysis as it is a typical area in southern part of Shandong. First, the related data, i.e., population, land, and economy of Jv County, is analyzed in order to determine the standards of per capita construction land and the compounded growth rate of population. Second, the theoretical potential is calculated based on per capita demand method, and compared with typical investigation methods. Then, per capita demand method is chosen to obtain the theoretical potential of rural residential area land consolidation. Next, analytic hierarch process is applied to obtain the weight of different factors, e.g., nature, economy, society, and the situation of land utilization. Then, the amendment coefficient is calculated by the sum of weighted value, which is used to obtain the realistic potential. At last, the level of potential is determined according to the potential coefficient, which is based on the realistic potential and the present residential area. The result shows that the consolidation potential of level 1, level 2, and level 3 covers $35.8 \%, 38.5 \%, 25.7 \%$ of the whole area, respectively. Meanwhile, as to the spatial distribution, the consolidation potential at the center is lower than that in the north and south, and the value in the south is relatively higher.
\end{abstract}

\section{Introduction}

At present, the contradiction between supply and demand of construction land was significant in China [1]. On the one hand, the phenomenon of "vacant villages" and less efficient usage exist in rural residential land. Obvious spatial differences can be observed, and it is more severe in less-developed hilly area [2]. On the other hand, with the rapid advance of urbanization and industrialization, demand for construction land is increasing, and urban construction land is tensioned for lacking of reserved cultivated land resources [3]. Thus, the government encourages returning rural construction land to cultivated land by the policy of rural residential consolidation [4]. Consolidation of rural residential area could optimize spatial layout of the rural settlement and effectively supply cultivated land resources, which is the inevitable choice of Chinese people to solve the contradiction in current land use [5]. The study of rural residential areas has become a hot issue in academic research aspect.

There are a large number of villages in southern part of Shandong, and distribution character of the villages is not unified. In this paper, Jv County is selected as a typical area of southern part of 
Shandong. Its consolidation potential and spatial distribution characters are analyzed. The results may provide a scientific reference for the rural residential consolidation in south of Shandong province.

\section{Introduction of Study Area and Research Methods}

Introduction of Study Area. Jv County is located in Rizhao city of Shandong province, which ranks the third in Rizhao city due to its rapid economic development. There are 21 towns (a total of 1260 villages) in Jv County, covering a total area of $1952.42 \mathrm{~km}^{2}$. The county has a population of 1.1998 million, and agricultural population is about 900000 . The total area of rural residential land is $166.22 \mathrm{~km}^{2}$, and the per capita of rural residential land is about $185.69 \mathrm{~m}^{2}$.

Research Methods. There are various methods in calculating rural residential potential, such as the method of per capita construction land, per family construction land, sampling typical points, and vacancy rate of rural residential land. The most widely used method is the method of per capita construction land. In this paper, due to the frequent changing of geography of Jv County, we will combine the methods of per capita demand and sampling typical points to measure theoretical potential of residential area. Then, an amendment coefficient is calculated by the sum of weighted value, which is used to obtain the realistic potential. The grade for development potentiality is decided by using clustering analysis, and is mapped by a GIS technology.

\section{The Calculation of Real Potential}

\section{The Calculation of Theoretical Potential.}

(1) Method of per capita construction land. The rural residential area for renovation during the planning period is $\Delta \mathrm{S}=\mathrm{S}_{0}-\mathrm{Q} \times \mathrm{P}$ where $\mathrm{S}_{0}, \mathrm{Q}$ and $\mathrm{P}$ represent current area of the rural residential land, standard area of per capita rural construction land and target number of population during the planning period, respectively.

There are two essential problems in this method, i.e., the determination of the standard area of per capita rural construction land, and the growth rate of rural population. Increase and decrease of rural residential land area is closely related to geomorphology [6-7]. Study area is located in the hilly district with different physiognomy types, and thus we first divide the rural land into three categories, i.e., mountains, hills and plains. Then, according to the standard of rural residential construction in Shandong province and the approval standard of rural residential land in Jv County, per capita construction land area was ultimately determined with the consideration of local economic development. For different land type, the per capita construction land area is $110 \mathrm{~m}^{2}$ in the plain district, $90 \mathrm{~m}^{2}$ in the hills district, and $100 \mathrm{~m}^{2}$ in the mountain district. In order to determine the growth rate of population, we first collect the data of rural population from 1995 to 2015. Then, with the help of SPSS, regression analysis is carried out by using different relation between year and growth rate. At last, the growth rate of population during the planning period is calculated to be $12.03 \%$, which corresponds with the state policy of having two children and the realistic status in Jv County.

(2) Method of sampling typical points. Due to the restriction of geography and economy, the residential area is sparsely distributed with the characteristics of covering small area, large number and severe differences. The smallest unit in landscape classification is a township, and even that scale is relatively large for $\mathrm{Jv}$ County. The reason is that potential coefficient calculated by per capita demand method is not consistent with the realistic situation. Thus, theoretical potential is modified by sampling typical points, and the result is shown in Table 1. 
Table 1 Realistic potential and potential level of each town in Jv County unit: ten thousand/hm²

\begin{tabular}{|c|c|c|c|c|c|c|c|c|}
\hline Town & $\begin{array}{l}\text { Rural } \\
\text { residential } \\
\text { area }\end{array}$ & $\begin{array}{c}\text { Rural } \\
\text { population } \\
\text { of } 2015\end{array}$ & $\begin{array}{l}\text { Theoretical } \\
\text { potential }\end{array}$ & $\begin{array}{l}\text { Complex } \\
\text { theoretical } \\
\text { potential }\end{array}$ & $\begin{array}{l}\text { Amendment } \\
\text { coefficient }\end{array}$ & $\begin{array}{l}\text { Realistic } \\
\text { potential }\end{array}$ & $\begin{array}{l}\text { Potential } \\
\text { coefficient }\end{array}$ & $\begin{array}{c}\text { Potential } \\
\text { level }\end{array}$ \\
\hline Longshan & 637.75 & 3.77 & 212.99 & 203.89 & 0.3717 & 75.79 & 0.12 & 3 \\
\hline Sangyuan & 867.08 & 4.48 & 362.32 & 277.21 & 0.376 & 104.23 & 0.12 & 3 \\
\hline Qishan & 1146.52 & 7.36 & 317.27 & 366.54 & 0.4081 & 149.58 & 0.13 & 3 \\
\hline Kushan & 557.37 & 2.04 & 327.52 & 200.65 & 0.5332 & 106.99 & 0.19 & 1 \\
\hline Zhonglou & 986.45 & 4.8 & 445.64 & 315.37 & 0.5675 & 178.97 & 0.18 & 1 \\
\hline Liuguanzhuang & 1197.11 & 6.11 & 577.54 & 450.23 & 0.3986 & 179.46 & 0.15 & 2 \\
\hline Xiazhuang & 1081.51 & 5.95 & 478.17 & 521.29 & 0.5309 & 276.75 & 0.26 & 1 \\
\hline Fulaishan & 913.43 & 4.58 & 449.01 & 343.54 & 0.3011 & 103.44 & 0.11 & 3 \\
\hline Xiaodian & 888.22 & 4.58 & 423.8 & 428.12 & 0.4482 & 191.88 & 0.22 & 1 \\
\hline Zhaoxian & 1036.04 & 6.2 & 407.35 & 409.23 & 0.3323 & 135.99 & 0.13 & 3 \\
\hline Yanzhuang & 702.85 & 3.23 & 375.32 & 318.77 & 0.3587 & 114.34 & 0.16 & 2 \\
\hline Zhailihe & 663.8 & 2.9 & 369.73 & 270.23 & 0.3842 & 103.82 & 0.16 & 2 \\
\hline Dongguan & 594.5 & 2.62 & 328.83 & 242.02 & 0.5904 & 142.89 & 0.24 & 1 \\
\hline Guozhuang & 553.98 & 2.32 & 318.73 & 225.53 & 0.3832 & 86.42 & 0.16 & 2 \\
\hline Luohe & 658.92 & 3.34 & 320.24 & 268.25 & 0.2799 & 75.08 & 0.11 & 3 \\
\hline Qiaoshan & 831.13 & 5.17 & 403.6 & 389.6 & 0.33 & 128.57 & 0.15 & 2 \\
\hline Lingyang & 644.12 & 3.5 & 289.21 & 257.65 & 0.3668 & 94.51 & 0.15 & 2 \\
\hline Changling & 587.15 & 3.08 & 274.83 & 234.86 & 0.3719 & 87.34 & 0.15 & 2 \\
\hline Dianzi & 594.01 & 3.45 & 244.17 & 219.78 & 0.4408 & 96.88 & 0.16 & 2 \\
\hline Anzhuang & 487.44 & 2.66 & 217.71 & 170.6 & 0.4358 & 74.35 & 0.15 & 2 \\
\hline
\end{tabular}

The Calculation of Realistic Potential. Potential degree of rural residential area is influenced by many factors, such as regional economic, natural factors and social factors [8-9]. In this paper, nine factors are selected from the aspects of nature, economy and society, which are per capita arable land, the land suitability for agriculture, government revenue, per capita income of farmers, rural population, the distance away from city center, farmers' will, the rural residential areas agglomeration degree, and ratio of farm land to rural residential areas. The aforementioned nine factors are used to calculate the amendment coefficient in analytic hierarchy process (AHP). The related formulas are shown in Eqn. (2) and (3).

The realistic potential $S_{r}$ is $S_{r}=S_{t} K_{a}$, where $S_{t}$, and $K_{a}$ represent the theoretical potential and the amendment coefficient, respectively. The amendment coefficient is $K_{a}=\sum_{\mathrm{i}=1}^{\mathrm{n}} \mathrm{w}_{\mathrm{i}} \cdot f_{\mathrm{i}}$, where $f_{i}$ and $w_{i}$ represent the value of each index and the corresponding weight, respectively.

\section{Consolidation Potential Analysis of Rural Residential Area}

Consolidation Potential Classification of Rural Residential Areas. According to "County Level Land Management Planning Procedures" (TD/T 1035-2013), potential level is graded using the potential coefficient, and potential coefficient is equal to the ratio of realistic potential to rural residential area. Consolidation potential is classified into three levels using the potential coefficient. The first level is greater than or equal to 0.18 , the secondary level is greater than or equal to 0.15 and less than 0.18 , and the third level is less than 0.15 . The classification results are shown in table 1. Consolidation potential classification of rural residential areas is mapped by using GIS software (Fig. 1). 


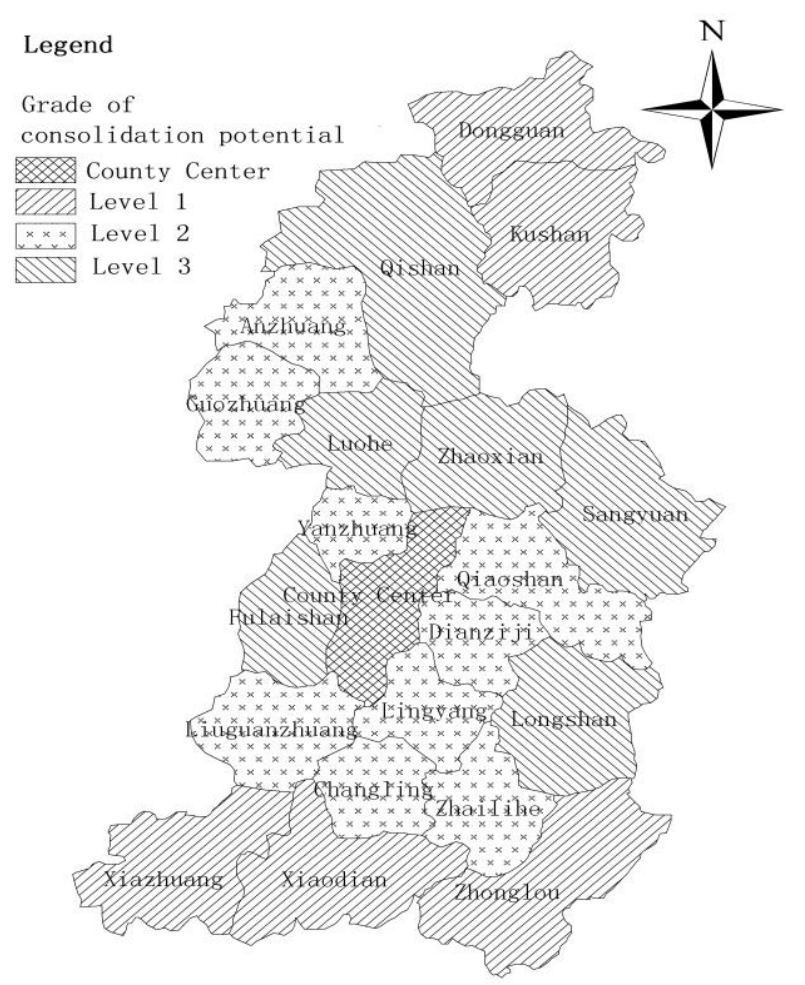

Fig.1 Spatial distribution of the consolidation potential

Spatial Distribution of Different Consolidation Potential Level.

(1) Spatial distribution of the first consolidation potential level. The realistic potential area of rural residential land in this level is 897.48 hectares, which is $35.8 \%$ of the total area. The average realistic potential coefficient is 0.22 , and the ratio of transforming from theoretical potential to realistic potential is $52.6 \%$. It mainly concentrates in five townships of the south and northeast in $\mathrm{Jv}$ County. The per capita rural residential area reaches $216.27 \mathrm{~m}^{2}$, which benefits from comprehensive high theoretic potential, convenient transportation and high per capita income. For example, in Xiazhuang town, there are a large number of tea plantations in recent years. Due to the development of the economic, people's living standards are improving, which leads to the phenomenon that new houses are built in other better places and original house sites are not abandoned. Thus, the residential area is enlarged, and these districts of consolidation potential level 1 should be taken as key areas for future consolidation process.

(2) Spatial distribution of the second consolidation potential level. The realistic potential area of this level is 965.69 hectares, which is $38.5 \%$ of the total area. The average realistic potential coefficient is 0.15 , and the ratio of transforming from theoretical potential to realistic potential is $38.1 \%$. The per capita rural residential area reaches $196.9 \mathrm{~m}^{2}$. There are nine towns in this level. Apart from the town of Anzhuang and Guozhuang, the other seven towns all locate around the center of county. Thus, the main regional features of this level are the short distance from the county center and convenient traffic condition. With the accelerating of new rural construction and the improvement of living standards of farmers, level 2 regions could be as medium-term consolidation areas.

(3) Spatial distribution of the third consolidation potential level. The realistic potential area of this level is 644.11 hectares, which is $25.7 \%$ of the total area. The average realistic potential coefficient is 0.12 , and the ratio of transforming from theoretical potential to realistic potential is $34.5 \%$. There are six towns in this level, which are Luohe, Qishan, Zhaoxian, Longshan, Fulaishan and Sangyuan. Based on its geography, towns of the level 3 are districted around those of level 2. The largest regional characteristics of this level are large population density, less-developed economy, and high ratio of land use. Level 3 regions could be as long-term consolidation areas. 


\section{Conclusion}

There are a large number of villages in southern part of Shandong, and distribution character of the villages is not unified. In this paper, Jv County is selected as a typical area of southern part of Shandong. First, the related data, i.e., population, land, and economy of Jv County, is analyzed in order to determine the standards of per capita construction land and the compounded growth rate of population. Then, the amendment coefficient is calculated by the sum of weighted value, which is used to obtain the realistic potential. The result showed that the consolidation potential of level 1 , level 2, and level 3 covers $35.8 \%, 38.5 \%, 25.7 \%$ of the whole area, respectively. Meanwhile, as to the spatial distribution, the consolidation potential at the center is lower than that in the north and south, and the value in the south is relatively higher.

\section{Acknowledgements}

This work was financially supported by the Development Project of Shandong Province Famous University (XYX2015038), the Open Fund of the State Key Laboratory of Soil and Sustainable Agriculture (Y20160007) and Talent Fund of Qingdao Agricultural University (1114344).

\section{References}

[1] W.Song, B.M.Chen and G.H.Jiang: Economic Geography. Vol.30(2010), p.1871(In Chinese)

[2] Y.S.Liu and Y.Liu: Geographical Research. Vol.29 (2010), p.35(In Chinese)

[3]X.S.Lu: Transactions of the Chinese Society of Agricultural Engineering. Vol.18 (2002), p.1(In Chinese)

[4]Y.H.Hu and G.F.Liu: Henan Science. Vol.34 (2016), p.125(In Chinese)

[5]H.L.Long, Y.R.Li and Y.S.Liu: Acta Geographica Sinica. Vol.64 (2009), p.1203(In Chinese)

[6] P.Sklenicka: Land Use Policy . Vol.23 (2005), p.502

[7]M.Mihara:Journal of Agricultural Engineering Research . Vol.64 (1996), p.237

[8] A. Bronstert, S. Vollmer and J. Ihringer: Physics and Chemistry of the Earth . Vol.20 (1995), p.321

[9]W.Song, B.M.Chen, Y.Zhang and J.Z.Wu: Chinese Geographical Science. Vol.22(2012), p.483 